\title{
The 1st International Workshop on Waves, Storm Surges and Coastal Hazards incorporating the 15th International Workshop on Wave Hindcasting and Forecasting
}

\author{
Val Swail $^{1}$ • Jose-Henrique Alves ${ }^{2}$ • Øyvind Breivik ${ }^{3,4}$ • Jennifer Brown ${ }^{5}$. Diana Greenslade ${ }^{6}$
}

Received: 19 February 2019 / Accepted: 22 February 2019 / Published online: 12 March 2019

(C) Springer-Verlag GmbH Germany, part of Springer Nature 2019

\begin{abstract}
Following the 1st International Workshop on Waves, Storm Surges and Coastal Hazards, which incorporated the 15th session of the long-standing the International Workshop on Wave Hindcasting and Forecasting, in September 2017 in Liverpool, United Kingdom, a topical collection has appeared in recent issues of Ocean Dynamics. Here, we give a brief overview of the 15 papers published in this topical collection as well as an overview of the widening scope of the conference in recent years. The continuing trend towards closer integration between the wave and ocean modeling communities is reflected in this workshop, culminating in the renaming of the workshop, while maintaining the connection with the three-decade long history of the wave workshop. This is also seen in this topical collection, with several papers exploring wave-generated storm surge, wave-tide contributions to coastal flooding, forcing a global ocean model with fluxes from a wave model and interaction between surface waves and sea ice.
\end{abstract}

Keywords Wave modeling · Wave hindcasting · Wave measurements · Wave theory · Coastal hazards · Storm surges · Water level forecasting

\section{History of the workshop}

The long history of the International Workshop on Wave Hindcasting and Forecasting has been previously described by Breivik et al. $(2015,2017)$ for the topical collections following the 13th and 14th International Workshops on Wave Hindcasting and Forecasting. At the 14th Workshop, held in Key West, Florida, in November 2015, it was decided that the

Responsible Editor: Jörg-Olaf Wolff

Val Swail

val.swail@gmail.com

1 Climate Research Division, Environment and Climate Change Canada, Toronto, ON, Canada

2 Environmental Modeling Center, National Centers for Environmental Prediction, National Oceanic and Atmospheric Administration, Silver Spring, MD, USA

3 Norwegian Meteorological Institute, Alleg 70, 5007 Bergen, Norway

4 The Geophysical Institute, University of Bergen, Alleg 70, 5007 Bergen, Norway

5 National Oceanography Centre, Liverpool, UK

6 Bureau of Meteorology, Melbourne, Australia next workshop would, for the first time, be held outside North America, hosted by the National Oceanography Centre in Liverpool, UK, 10-15 September 2017. At the same time, in a continuing effort to further broaden the scope of the workshops to foster closer integration between the wave and ocean modeling communities, such as the emerging priority of multihazard early warning systems (MHEWS) for coastal inundation resulting from the combined effects of waves, storm surges, tides, etc., e.g., the WMO Coastal Inundation Forecasting Demonstration Project (CIFDP), the workshop was renamed as the 1st International Workshop on Waves, Storm Surges and Coastal Hazards. The workshop continues to explicitly acknowledge the International Wave Workshop, so as not to lose the successful legacy of the previous workshops, including the workshop web site www.waveworkshop.org. In the continued spirit of increasing international engagement in the workshop, and fostering even greater collaboration, the 2nd International Workshop on Waves, Storm Surges and Coastal Hazards, incorporating the 16th International Workshop on Wave Hindcasting and Forecasting, will be held in Melbourne, Australia, hosted by the University of Melbourne, 10-15 November 2019.

It is now more than 30 years since the first International Workshop on Wave Hindcasting and Forecasting was held in 
Halifax, Nova Scotia, Canada, in September 1986. As described by Breivik et al. (2015), the research tools and the topics have changed over the years, but we can still recognize the primary objectives of the first workshop, which are the following:

- Provide a forum for the exchange of ideas and information related to wind and wave hindcasting and forecasting, including modeling, measurement, and past and future states of the climate

- Coordinate ongoing research and development initiatives

- Discuss priorities for future research and development

\section{The 1st Wave, Surge and Coastal Hazards Workshop}

The 1st International Workshop on Waves, Storm Surges and Coastal Hazards, incorporating the 15th International Workshop on Wave Hindcasting and Forecasting (henceforth referred to as the Workshop) was held in Liverpool, UK, from 10 to 15 September 2017. Given the mixed response to the firsttime experiment with parallel sessions at the 14th workshop in Key West, Florida, where many participants felt that the strength of the workshop series had been the plenary format, with wideranging discussion, and exposure to related scientific disciplines, the 2017 workshop returned to a plenary format for all presentation sessions. This resulted in a reduction in the number of oral presentations to 85 , but saw a greatly increased poster program, with five hour-long dedicated poster sessions to accommodate 60 wide-ranging posters. The workshop welcomed 156 participants, 51 of whom were women, a far cry from the 6th Wave Workshop in 2000, where there were 2 women in a meeting of 80 participants. The session topics were the following:

- Wave measurement

- Wave design criteria

- Observations and analysis of wave impacts

- Advances in storm surge forecasting

- Storm surge operational forecasting

- Coastal hazard forecasting

- Wave models and forecasting

- Wave forecasting

- Wave theory

- Storm surge climate

- Storm surge case studies in a changing climate

- Climate change and coastal flood risk

- Extreme water levels at the coast

- Wave hindcasting

- Wave climate

- Wave climate change

In addition to the general sessions, the workshop had theme sessions for waves, storm surge, and coastal hazards, as is always the case for this workshop series. The special topics were (i) "Developing improved methods for wave prediction in complex conditions and environments"; (ii) "Wave measurements, including user requirements, best practices and evaluation"; (iii) "Developing Tools for Quantifying Future Coastal and Offshore Risks and Resiliency"; and (iv) "Advances in storm surge modeling and forecasting."

Fifteen papers relating to the workshop have been published in this topical collection. A brief summary of these papers follows.

Wave measurement is a foundational aspect of all waverelated research and applications, including model development and validation, forecasting and verification, satellite wave calibration and validation, and direct use in wave climate and design statistics. This is why wave measurement remains as a theme session in the workshop. In this collection, Wyatt (2019) investigates the ability of high frequency (HF) radars to measure the "first five" Fourier coefficients of the directional wave spectrum. It is found that HF radars are able to measure directional wave parameters, but the quality of the spectra varies strongly with measurement quality, and it varies among the five parameters (first order parameters are more robust) and with the wave frequency (higher frequencies are more robustly measured).

Wave forecasting and the related development and validation of wave models of ever increasing sophistication, resolution, and products, e.g., new probabilistic versus deterministic approaches, are a core topic for this workshop. Several authors in this topical collection focused on such developments in wave forecasting.

Forecasting of waves under extreme conditions such as tropical cyclones is vitally important for many offshore industries. Zieger et al. (2018) describe a new ensemble-based wave forecasting system introduced at the Australian Bureau of Meteorology for the northwest Western Australia region, an area subject to on average 11 tropical cyclones per season (Dowdy 2014), with a large number of offshore oil and gas reserves. Previously, wave forecasts have been limited to products from deterministic operational wave models forced by deterministic atmospheric models, with relatively coarse resolution, limiting the accuracy of these products under tropical cyclone conditions. A new dedicated 8-km resolution grid was nested in the global wave model, forced with winds from a 51 member atmospheric ensemble, to take into account the uncertainties in location, intensity, and structure of a tropical cyclone system. The system is designed to operate in real time during the cyclone season providing 10-day forecasts. Verification against observations demonstrates that the new system shows significant improvement over the ECMWFEPS on each of the metrics examined, although the amount of verification data is relatively small. The improvement in ensemble skill was attributed to the reduction of forecast error for wind-seas. The verification also showed marked 
improvement in ensemble spread, making it more likely to capture extreme events giving greater confidence to decision-making in complex situations.

Caires et al. (2018) describe the development of a state-ofthe-art coastal wave forecast system for the East Coast of Korea. In this study, the quality of the input wind was identified as the main factor influencing the quality of the wave results, so the effectiveness of adjusting the wind fields by means of data assimilation using an ensemble Kalman filter data assimilation scheme was explored. The validation of the model hindcasts during the considered storm period shows that the model results are at least as accurate as those of other highquality local models, and that the model is able to provide predictions of coastal waves meeting available benchmarks.

Kita et al. (2018) investigate the wave growth under explosive cyclones (ECs) in the Northwestern Pacific Ocean. ECs are defined as low-pressure systems that deepen below $980 \mathrm{hPa}$ by more than $12 \mathrm{hPa}$ in $12 \mathrm{~h}$. It is found that ocean waves develop very differently under ECs than under tropical cyclones. As ECs evolve very rapidly, the ocean wave field lags behind the peak wind speed by several hours. In a case study of an EC that occurred in January 2013, the wave spectrum indicates that a warm front played a critical role in generating distinct ocean wave systems in the warm and cold zones along the warm front. Both the warm and cold zones have narrow directional and frequency spectra. In contrast, the ocean wave field in the third quadrant (rear left area relative to the propagation direction) of the EC is composed of swell and wind-sea systems propagating in different directions.

Nose et al. (2018) consider the sea-state predictability in an ice-free Beaufort Sea in two cases from the fall of 2016 and conclude that, although ice coverage influenced the results through changes of the fetch, the most important factor was the quality of the wind fields. This highlights the difficulty in correctly modeling the atmosphere in an area with rapid ice growth. This is exacerbated by the dearth of observations in the Arctic region.

Law Chune and Aouf (2018) report the impact of forcing a global NEMO ocean model with fluxes from the MFWAM wave model. A three-year sensitivity study of three waverelated processes, namely (i) the wave-modulated surface stress, (ii) the Coriolis-Stokes force and the Stokes drift advection of tracers and mass, and (iii) the sea-state dependent mixing (based on the flux of turbulent kinetic energy from breaking waves), reveals a significant reduction of sea surface temperature (SST) bias in the Tropical Atlantic Ocean. This is mainly due to the more realistic momentum flux (surface stress) calculated from the wave model.

Wave hindcasts and the development of new hindcasting approaches have long been a hallmark of the workshop. In this instance, Markina et al. (2018) hindcast waves in the North Atlantic using Wave Watch III to investigate sensitivity to spectral nudging. They show how the accuracy of a wind wave hindcast is dependent on a reliable forcing field. An annual cycle is simulated using ERA-Interim reanalysis to force a WRF numerical weather prediction system. The proposed nudging formulation provides a reliable approach for long-term climate studies. It improves the pattern correlation between WRF and ERAInterim winds. Dynamical downscaling to increase the horizontal resolution also allows the simulation of extreme wind speeds and the associated higher waves. In coastal regions, the differences were up to $20 \%$ in mean wind speed and wave height. Accurate representation of coastal conditions is critical for storm impact studies. The presented forcing approach is thus suitable for multidecadal hindcast reanalysis of basin-scale ocean dynamics.

End user applications are also important and reflect the endto-end scope of the workshop. Knowledge about the statistics of waves, in particular extreme waves, is required for the design and operation of offshore structures, and two papers in this collection address aspects of this issue. Kvingedal et al. (2018) note that, typically, standard models are applied, such as secondorder models for the statistics of wave heights and crest heights and regular wave theory for prediction of loads. However, recent research indicates that crest heights may be larger than the standard models specify, due to (1) higher-order effects and (2) area effects. In their study, motivated by the need for more knowledge about these higher-order effects for individual wave heights and crest heights, a long record of field measurements of individual wave heights and crest heights from a location with water depth $190 \mathrm{~m}$ in the northern North Sea has been analyzed and compared to well-known theoretical distributions. The main objective of the analysis was to identify and recommend a distribution function for individual wave height and crest height for practical design purposes for such water depths. For wave heights, the Rayleigh distribution was found to form a conservative upper bound, while the Forristall (1978) distribution was considered to show a good accuracy, though somewhat conservative in the most severe sea states. For crest heights, the Rayleigh distribution was found to be non-conservative, while the Forristall (2000) distributions for long- and short-crested sea both provided reasonable descriptions. Based on their study, the Forristall distributions for individual wave height and crest heights in longcrested seas were considered to provide the most appropriate descriptions of these measured wave data.

Teich et al. (2018) present the long-term statistics of potentially hazardous sea states in the North Sea based on a wave hindcast of the period 1958-2014. Traditionally, significant wave height and wave period have been used to identify hazardous sea states; however, these give only limited information about the risk posed to ships and marine structures. Teich et al. (2018) investigate a number of indices that go beyond wave height and wave period, for example, rapid changes in sea state, wave spreading, and wave steepness.

Since the incorporation of storm surge topics into the workshop scope in 2013, there has been increasing content dealing with storm surge and its interactions with waves and coastal 
processes. Several papers are published in the present collection which deal with real-time storm surge warning systems, storm surge risk, and modeling of coupled wave-tide-surge interactions.

Lin et al. (2018) describe the development and evaluation of a storm surge warning system for Taiwan. They find that the unique topographic nature of Taiwan has an influence on the most appropriate forcing to use for the storm surge model. In particular, they show that for slow-moving typhoons, which tend to interact more significantly with topography than fast-moving typhoons, it is necessary to use realistic numerical weather prediction (NWP) fields (with adjustments to initial wind fields) rather than parametric typhoon wind forcing.

Choi et al. (2018) revisit the 1953 North Sea storm surge, but unlike many studies, they focus on the wave-generated hazard. Through numerical experiments using a coupled wave-tidesurge model, they identify wave setup has a $10 \%$ contribution to the storm surge peak in the Wash and delta coast areas of the Netherlands. This result is obtained from the application of a barotropic ADCIRC model coupled to the shallow water wave model SWAN, forced by ERA-20C reanalysis atmospheric data. A constant correction factor of 1.2 is applied to reproduce the $10 \mathrm{~m}$ winds. The coupling is achieved through model "leap frogging" in time so each model incorporates information from the other. Validation is performed using historic tide gauge and wave records in addition to related literature.

Ganske et al. (2018) describe two approaches to identify low probability, but plausible storm surge events. This study provides a detailed comparison of events to demonstrate how the method can inform planning and design of adaptive coastal management strategies in response to changing climate conditions. It is shown that more than the effective wind magnitude is required to project the highest storm surges. The wind duration exceeding a threshold and storm track also play a key role. However, the effective wind is an approach that can be used when there is no water level data available. This approach can be used to identify high storm surges for further impact assessment to better inform coastal management planning and coastal scheme design.

Lewis et al. (2019) consider the impact of wave-tide interactions on nearshore wave height within the Irish Sea in the context of coastal flood risk. They found that in some regions, wave heights at high water were $20 \%$ higher when coupled processes were included. Exploring the impact of different spatial resolution on their modeling results, they found that wave-tide interaction was sensitive to spatial resolution due to the effect of tidal current changes around bathymetric features.

While the workshop has always had a strong program related to wave hindcasting and forecasting (now expanded to storm surge), and the end user applications, it also deals with topics which are further up the research chain, contributing to the end-to-end nature of the meeting, including nonlinear wave theory, freak waves, and solitons. Two papers which deal with these types of research are contained in this topical collection.

Fujimoto et al. (2019) investigate the geometry and possible generation mechanisms of freak waves. The authors focus on two deep-water measurements of freak waves observed by a GPS buoy located offshore the Tohoku area, in Japan, during the passage of Typhoon Lupit in 2009. A hybrid approach is used where a phase averaged model initializes phase-resolved simulations, generating an ensemble of realizations based on observed and simulated directional spectra. Rather than focusing on the probability of freak wave occurrence; the authors examine wave shapes to find out that freak waves with longer lifetimes are associated with narrower spectra and have more pronounced front-to-rear asymmetry and crescent shape deformation of the crest, which are both characteristics of nonlinear wave groups. By comparing freak wave lifetimes from narrow and broad spectra, their study shows that the sea state controls the distribution of lifetimes, whereby the number of nonlinear wave groups increases for a narrower spectrum. The authors conclude that four-wave quasi-resonance and dispersive focusing are responsible for freak wave generation, but their relative significance depends on spectral broadness. An important insight from this paper is that given the importance of nonlinear wave-wave interactions to freak wave generation, current spectral models used in operational wave forecasts using rough approximations to that process are likely unable to properly represent the likelihood of freak wave occurrence reliably.

Finally, Osborne et al. (2019) provide account of the application of nonlinear Fourier analysis (NLFA) methods to recorded time series of surface wave data. In the NLFA approach, a wave record is represented by a multidimensional, quasi-periodic Fourier series that allows separating components by increasing levels of nonlinearity, using sine waves, Stokes waves, and phase-locked Stokes waves arising from modulational instability, the so-called "breather packets." The paper provides a clear demonstration of how the standard Fourier analysis can be "upgraded," to give useful information on nonlinear features of a wave record. This goal is achieved via a clear description of underlying methods, and an illustrative application to recorded waves from the Currituck Sound data set (Long and Resio 2007). The end result is a manuscript that brings together mathematical approaches for fully nonlinear waves in clear and compelling ways, and challenge the Gaussian approximation often considered in the analysis of wave data. The analysis reveals the presence of a surprisingly large number of breather trains in the Currituck Sound data set, and that only $5 \%$ of the energy is carried by small amplitude sine and Stokes wave components, whereas $95 \%$ of the NLFA components are found to consist of breather trains.

The 15 articles in this topical collection show the continued breadth of the workshop. However, a number of excellent 
proceeding papers can also be found online at www. waveworkshop.org, where the long history of the workshop has been carefully archived. After a very successful leap across the Atlantic for this workshop, we now look forward to the first visit to the Southern Hemisphere in 2019, and an even more international gathering in the coming years.

Acknowledgments The conference co-chairs would like to express their gratitude to the organizers and sponsors: Liverpool Institute for Sustainable Coasts and Oceans (LISCO), the UK National Oceanography Centre, the Taylor Engineering Research Institute at the University of North Florida, Environment and Climate Change Canada, and the WMO-IOC Joint Technical Commission for Oceanography and Marine Meteorology (JCOMM). More information about the conference can be found at http:// www.waveworkshop.org. ØB gratefully acknowledges funding from the Research Council of Norway through MAROFF grant 256521. We are grateful to Springer (publisher of Ocean Dynamics) for taking the subject into consideration for a topical collection.

\section{References}

Breivik Ø, Swail V, Babanin A, Horsburgh K (2015) The international workshop on wave hindcasting and forecasting and the coastal hazards symposium. Ocean Dyn 65(5):761-771. https://doi.org/10. 1007/s10236-015-0827-9 arXiv:1503.00847. 13th wave special issue

Breivik Ø, Alves JH, Greenslade D, Horsburgh K, Swail V (2017) The 14th international workshop on wave hindcasting and forecasting and the 5th coastal hazards symposium. Ocean Dyn 67(3-4):551556. https://doi.org/10.1007/s10236-017-1033-8 14th wave special issue

Caires S, Kim J, Groeneweg J (2018) Korean East Coast wave predictions by means of ensemble Kalman filter data assimilation. Ocean Dyn 68(11):1571-1592. https://doi.org/10. 1007/s10236-018-1214-0

Choi BH, Kim KO, Yuk JH, Lee HS (2018) Simulation of the 1953 storm surge in the North Sea. Ocean Dyn 68(12):1759-1777. https://doi. org/10.1007/s10236-018-1223-z

Dowdy AJ (2014) Long-term changes in Australian tropical cyclone numbers. Atmos Sci Let 659 15(4):292\{298, doi:https://doi.org/10. $1002 /$ as 12.502

Forristall GZ (1978) On the statistical distributions of wave heights in a storm. J Geophys Res 83:2353-2358

Forristall GZ (2000) Wave crest distributions: observations and secondorder theory. J Phys Oceanogr 30:1931-1943
Fujimoto W, Waseda T, Webb A (2019) Impact of the four-wave quasiresonance on freak wave shapes in the ocean. Ocean Dyn 69(1): 101-121. https://doi.org/10.1007/s10236-018-1234-9

Ganske A, Fery N, Gaslikova L, Grabemann I, Weisse R, Tinz B (2018) Identification of extreme storm surges with high-impact potential along the German North Sea coastline. Ocean Dyn 68(10):13711382. https://doi.org/10.1007/s10236-018-1190-4

Kita Y, Waseda T, Webb A (2018) Development of waves under explosive cyclones in the northwestern Pacific. Ocean Dyn 68(10):14031418. https://doi.org/10.1007/s10236-018-1195-z

Kvingedal B, Bruserud K, Nygaard E (2018) Individual wave height and wave crest distributions based on field measurements from the northern North Sea. Ocean Dyn 68(12):1727-1738. https://doi.org/ 10.1007/s10236-018-1216-y

Law Chune S, Aouf L (2018) Wave effects in global ocean modeling: parametrizations vs. forcing from a wave model. Ocean Dyn 68(12):1739-1758. https://doi.org/10.1007/s10236-0181220-2

Lewis MJ, Palmer T, Hashemi R, Robins P, Saulter A, Brown J, Lewis H, Neill S (2019) Wave-tide interaction modulates nearshore wave height. Ocean Dyn 69(3):367-384. https://doi.org/10.1007/s10236018-01245-Z

Lin MY, Sun WY, Chiou MD, Chen CY, Cheng HY, Chen CH (2018) Development and evaluation of a storm surge warning system in Taiwan. Ocean Dyn 68(8):1025-1049. https://doi.org/10.1007/ s10236-018-1179-z

Long CE, Resio DT (2007) Wind wave spectral observations in Currituck Sound, North Carolina. J Geophys Res 112(1-21):C05001. https:// doi.org/10.1029/2006JC003835

Markina M, Gavrikov A, Gulev S, Barnier B (2018) Developing configuration of WRF model for long-term high-resolution wind wave hindcast over the North Atlantic with WAVEWATCH III. Ocean Dyn 68(11):1593-1604. https://doi.org/10.1007/s10236018-1215-z

Nose T, Webb A, Waseda T, Inoue J, Inoue K (2018) Predictability of storm wave heights in the ice-free Beaufort Sea. Ocean Dyn 68(10): 1383-1402. https://doi.org/10.1007/s10236-018-1194-0

Osborne A, Resio DT, Costa A, Ponce de Leon S, Chiviri E (2019) Highly nonlinear wind waves in Currituck Sound: dense breather turbulence in random ocean waves. Ocean Dyn 69(2):187-219. https://doi.org/10.1007/s10236-018-1232-y

Teich T, Groll N, Weisse R (2018) Long-term statistics of potentially hazardous sea states in the North Sea 1958-2014. Ocean Dyn 68(11):1559-1570. https://doi.org/10.1007/s10236-018-1210-4

Wyatt L (2019) Measuring the ocean wave directional spectrum 'first five' with HF radar. Ocean Dyn 69(1):123-144. https://doi.org/10. 1007/s10236-018-1235-8

Zieger S, Greenslade D, Kepert JD (2018) Wave ensemble forecast system for tropical cyclones in the Australian region. Ocean Dyn 68(45):603-625. https://doi.org/10.1007/s10236-018-1145-9 